\title{
La tecnología educativa
}

\section{y su incorporación en el campo académico de la comunicación}

\section{LUZ ZARETH MORENO*}

Resumen. La investigación que se presenta parte de la orientación teórica de la Tecnologia Educativa y mediante un análisis estadístico de corte no experimental de tipo transversal sobre los tipos de tecnologias que se usan predominantemente en el salón de clase, el uso que se bace de éstas, la capacitación con que se cuenta para emplearlas como recursos didácticos $y$ las condiciones institucionales, personales $y$ culturales que afectan al docente para incorporar la tecnologia educativa en los procesos de enseñanza-aprendizaje formales, se observa cierta incompetencia en la materia. Los resultados indican que, al menos en la Licenciatura de Ciencias de la Comunicación de la Universidad Latina de América de Morelia, donde se realizó el estudio, es recurrente el uso que los docentes hacen de las tecnologias. El medio más utilizado es el proyector de acetatos seguido por el video; no obstante el becho de que lo utilicen, como se observó en los resultados, no implica efectividad o cambios en el proceso de enseñanza-aprendizaje. En este caso, pese a que los profesores conocen un poco de la temática, se advierte un desconocimiento parcial de las ventajas $y$ desventajas que las tecnologías ofrecen en el ámbito de la educación, asi como en lo relativo a la incorporación estratégica de éstas.

\section{Introducción}

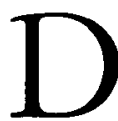
esde sus inicios, el campo de la comunicación ha sido uno de los más vulnerables a los cambios socioculturales y tecnológicos del entorno. Lo anterior no sólo ha impactado la disciplina desde el punto de vista epistemológico, sino también en lo que se refiere

- Especialista en comunicación educativa. Universidad Latina de América, Morelia, Michoacán. Correo electrónico: lzmoreno@unla.edu.mx 
a la educación que se gesta en las diferentes instituciones donde existe la Licenciatura en Ciencias de la Comunicación (LCC), Ciencias de la Información e incluso, Periodismo. Sin embargo, estos procesos de enseñanzaaprendizaje no se han explorado lo suficiente como para conocer lo eficaz o no que resultan los diferentes mecanismos y estrategias empleadas por el docente dentro del aula para favorecer el desarrollo cognitivo de los estudiantes.

La Tecnología Educativa (TE) como disciplina que se vincula directamente con aspectos teórico-prácticos de la enseñanza se hace necesaria en el campo académico de la comunicación ya sea a través de su incorporación en la parte de diseño, desarrollo, organización o utilización (Cabero, 2001). Si se piensa que en la TE confluyen aspectos de las teorías de la comunicación, semiótica, estudios sociales de la ciencia y tecnología y lo relativo a desarrollos tecnológicos, entonces podría pensarse que las aportaciones resultantes de esta unión llevarían a considerar al proceso de aprendizaje como un proceso comunicativo.

En tanto que actualmente se observan avances tecnológicos que han modificado las formas en las que se transmiten los mensajes y se genera la información, la existencia de estudios sobre el papel que tienen diversas herramientas tecnológicas como el video, la televisión, el proyector de acetatos, el proyector de diapositivas y la computadora en el aula resulta primordial. Si se parte de la concepción de que "Todo proceso que suponga un transporte de información y cuyo destinatario sea el ser humano, lo entenderemos como: comunicación" (Rodríguez Diéguez, citado por Cabero, 2001), se puede afirmar que la escuela en este contexto de avances tecnológicos se ha quedado rezagada, pues se ha convertido en un receptáculo de hombres y mujeres acostumbrados a lecturas diferentes de las que predominan en las instituciones educativas.

Con esta panorámica, el trabajo se centra en investigar el uso didáctico de los recursos o herramientas tecnológicas (video, proyector, computadora, etcétera) dentro de las Licenciaturas en Ciencias de la Comunicación. La información que se proporciona es fruto de la primera parte de un estudio realizado en esta carrera en la Universidad Latina de América (UNLA) de Morelia, cuyo objetivo general fue realizar una propuesta de incorporación de la TE en las escuelas de comunicación para contribuir a un mejor desarrollo del proceso de enseñanza-aprendizaje, con base en el análisis del uso didáctico de los recursos tecnológicos que los docentes efectúan dentro del aula.

En tanto que, como ya se ha observado, la comunicación es un proceso que está presente en la vida de todo ser humano, pero que además en función de su efectividad en la educación formal advierte en el individuo la posibilidad de contribuir a un mejor desarrollo de la actividad de enseñanza y aprendizaje, preguntar sobre la incursión de la tecnología, pero, sobre todo, la TE en particular, resulta prioritario en este trabajo, 
muestra de ello es la pregunta de investigación rectora ¿Cómo están utilizando la TE los profesores del área de Ciencias de la Comunicación y de qué manera se puede eficientar el desarrollo del proceso de enseñanza-aprendizaje? A partir de la cual se desprenden cuestionamientos adicionales: ¿se emplea la TE en las escuelas de comunicación?, ¿para qué se usa la TE en el área de la comunicación?, ¿utilizan los docentes herramientas tecnológicas?, ¿cómo utilizan estas herramientas?, ¿cuáles son las herramientas tecnológicas más usadas? y, ¿es necesario que los docentes reciban capacitación en cuanto al manejo didáctico de las tecnologías en el proceso de enseñanza-aprendizaje?

Las respuestas a dichos planteamientos podrán ser observadas de manera sintética a lo largo del presente artículo mediante el análisis teórico y los datos provenientes del cuestionario aplicado a 31 docentes de la LCC en el periodo semestral enero-mayo de 2004. Cabe señalar que, aunque el estudio que se realizó no es una muestra representativa de lo que sucede a nivel nacional en las escuelas de comunicación, bien puede servir como antecedente y ejemplificar la situación de este campo académico en lo relacionado a procesos pedagógicos.

\section{¿Qué es la Tecnología Educativa?}

Alrededor de la TE subyace un campo de amplias magnitudes que aún no acaba de ser explorado. Diferentes ciencias y disciplinas han contribuido a la formación de un marco contextual que la sitúa en un punto en el que su definición resulta compleja. Lo anterior obedece en parte a la forma en la que se origina el término y al momento histórico-social en la que se le define. No obstante, si se toma en cuenta el contenido semántico de la expresión habrá que considerar, por un lado, lo correspondiente a la tecnología y, por otro, lo que se refiere a la educación.

Desde la perspectiva de Cabero (2001), se piensa que la orientación tecnológica lejos de provenir de los avances que en este orden enfrenta el ser humano, se remite directamente al vocablo griego technologia, el cual engloba por una parte a la teckné (arte, destreza) y por otra, al logos (tratado, palabra). Desde este punto de vista se trata de una teoría de la técnica, es decir, la aplicación de técnicas apoyadas en un cuerpo teórico de conocimientos.

La tecnología, dice García-Varcárcel (2003), se sitúa entre la ciencia y la técnica, en tanto que a la primera debe los componentes teóricos y a la segunda, las ejecuciones prácticas orientadas a la resolución de problemas, el desglosarlo implica pensar en la ciencia como quien aporta formas de saber, en la tecnología como las formas de hacer con base en conceptos científicos y en la técnica como la habilidad práctica de adecuar medios y fines. En este contexto, si la tecnología es la organización y 
aplicación de conocimiento para el logro de fines prácticos, del mismo modo incluye manifestaciones físicas como las máquinas y herramientas, pero también técnicas intelectuales y procesos utilizados para resolver problemas y obtener los resultados deseados (Kast y Rosensweig, 1988, citados por Onteanqui, 2004). Esto aleja la concepción instrumentalista de ver a la tecnología como una herramienta que satisface únicamente fines y necesidades de quienes la usan con valores subordinados a otras esferas sociales, y nos acerca a una visión más crítica que la interpreta como la práxis tecnológica que antes de ser una aplicación de sí misma es una forma de conocimiento (Fainhole, 2001).

Castillejo por otro lado, concibe a la educación como un proceso de perfeccionamiento intencional asistido por la influencia sistematizada del educador dentro de un contexto sociocultural, es decir, un proceso interior y personal que es dirigido de manera intencional e influido por el medio (1985, citado por García-Varcárcel, 2003). Al considerarlo, así tiene cabida la TE como disciplina que se relaciona con los procesos de enseñanza-aprendizaje, esto a pesar de que atraviesa por un momento de redefinición - de hecho nunca ha dejado de estarlo-. Por lo tanto, desde la perspectiva de Cabero (2001), el término es integrador - conformado por diversas ciencias, tecnologías y técnicas-, vivo - sufre transformaciones continuamente-, polisémico - ha tenido diferentes significados-, y contradictorio - provoca defensas radicales y oposiciones frontales-.

Las concepciones sobre lo que es la TE varían de un autor a otro, dependiendo de la forma en la que se piensa la educación, la enseñanza $\mathrm{y}$, desde luego, el aprendizaje. Las visiones de los educadores e involucrados en esta temática son un reflejo de las necesidades y preocupaciones determinadas por el momento histórico en el que surgen. De ahí que su conceptualización haya transitado "desde un enfoque instrumentalista, pasando por un enfoque sistémico de la enseñanza centrado en la solución de problemas, hasta un enfoque más centrado en el análisis y diseño de medios y recursos de enseñanza que no sólo habla de aplicación, sino también de reflexión y construcción del conocimiento" (Prendes, 1998, citado por Marqués, 1999).

Las diferencias entre las formas de pensar a la TE se centran en lo que se refiere al objeto de estudio, a las líneas de investigación y a los campos de aplicación. Hay quienes la consideran una forma sistemática de diseñar, desarrollar y evaluar el proceso de enseñanza-aprendizaje, así como también quienes la conciben como un campo que se encarga de estudiar los medios en la enseñanza o como una rama dentro de la Didáctica. Asimismo, en algunos autores prevalece la idea de verla como un campo interdisciplinario mientras que otros la orientan a los modelos de aprendizaje, así como al análisis desde las teorías del currículum.

La TE es susceptible de abarcar al menos cinco aspectos: lo que tiene que ver con la utilización (uso de los medios, difusión de innovaciones, 
implementación y características del estudiante), lo referente a la organización (en cuanto al proyecto, los recursos y la información), el proceso de evaluación (análisis de problemas que implica una evaluación sumativa y formativa), el diseño (referido al mensaje y con base en lineamientos institucionales), y el desarrollo tecnológico (medios impresos, audiovisuales, informáticos, etcétera). Debido a esto, se puede concluir que la TE es un espacio que se ocupa no sólo de aspectos aplicados (diseño de medios y materiales, diseño curricular, propuestas para resolver problemáticas a las que se enfrentan los docentes en la práxis educativa, etcétera), sino también de reflexiones y teorías sobre lo que representan para la enseñanza los medios desde el punto de vista didáctico, comunicativo y social.

La TE, dice García-Valcárcel (2003), es una disciplina a través de la cual podemos preguntarnos cuál es el significado y aportación de las tecnologías al entorno, qué lecturas se pueden realizar de la sociedad de la información, cómo se puede integrar el desarrollo tecnológico en la educación y demás cuestiones que engloban aspectos importantes vinculados a la búsqueda constante de formas diferentes de pensar y hacer significativa la práctica educativa.

\section{La comunicación en la Tecnología Educativa}

Si la definición de la TE ha sido compleja, no lo es menos su conformación teórica, la cual ha sido perfilada gracias a las aportaciones de la teoría de los sistemas, la sociología de la educación, la didáctica del currículum y otras entre las cuales destaca la teoría de la comunicación debido a que la relación que se gesta entre comunicación y educación es sumamente estrecha. Se puede afirmar que sin la primera no se puede desarrollar el acto educativo y que todo proceso comunicativo, por otro lado, trae en consecuencia aprendizaje, incluso aunque no sea su objetivo hacerlo.

Si se parte del sentido etimológico del término, el cual proviene del vocablo latino comunicare, que significa la acción de poner en común (Maldonado, 1998), en la TE se aprecia que el propósito va más allá, pues interesa el proceso de asimilación que se da en el educando. Es necesario considerar que se aprende de manera directa o mediatizada; la última forma es la más utilizada, sobre todo en el ámbito educativo formal, donde la experiencia de aprendizaje se realiza mediante la representación icónica -aprendizaje por observación-y la representación simbólica -códigos del lenguaje-. De ese modo, el aprendizaje es una experiencia basada en procesos de comunicación humana (Luviano y Alonso, 1997).

Sin embargo, la relación entre comunicación y educación a lo largo de la historia ha atravesado por diferentes concepciones: la comunicación 
como control, donde el aula funcionaba gracias a la mirada del docente y de la misma institución; luego, una segunda tendencia fue el reclamo de que lo comunicacional estaba dado en el maestro-actor; es decir, él era el que importaba, su postura, sus ademanes, sus desplazamientos, etcétera; más adelante, se dijo que el educador era un tecnólogo, por lo que su base suponía un esquema emisor-mensaje-receptor, en el cual el emisoreducador era quien controlaba y preveía todo; por último, una directriz más es la que se relaciona a los medios audiovisuales y su empleo en el aula que va de la mano actualmente con la incorporación de las computadoras (Prieto, 1999).

La comunicación es un elemento inseparable de todos los procesos vinculados con el conocimiento y la sociedad (Perelló, 1992, citado por Ferrer, 1997); por eso, para la TE, el impacto de la comunicación es trascendente, ya que la educación es considerada como un proceso de comunicación el cual debe realizarse de manera eficaz para mejorar los aprendizajes de los estudiantes (Marqués, 1999). Vista como un acto mediador, la comunicación en el aula se efectúa mayoritariamente con el modelo tradicional a través del docente y de los libros, pero en la actualidad eso es parcial, ya que han incursionado también recursos tecnológicos como el video, la radio, la computadora, y el proyector de acetatos, etcétera que, en consecuencia, han reorientado este proceso mediador. Al respecto, la mediación, más que pretender manipular o distorsionar la información, debe procurar en los estudiantes resignificar el objeto por medio de la investigación, el análisis y la construcción del propio conocimiento para obtener aprendizaje significativo (Luviano y Alonso, 1997).

La mediación pedagógica implica tres aspectos complementarios: el contenido, el proceso de aprendizaje y la forma. En el primero, el maestro selecciona, estructura y organiza la información de tal manera que resulte accesible, lógica, pertinente $y$, sobre todo, interesante y amena para el educando; en el segundo, se propone una secuencia de actividades que relacionen el contenido con la experiencia y el contexto del educando, a la vez que propicien formas participativas que fomentan la creatividad, la investigación y la autoformación; en la tercera se seleccionan los recursos expresivos que mejor correspondan a la naturaleza del contenido y que, desde luego, se vinculen también a cuestiones de estética y percepción (Luviano y Alonso, 1997).

Desde esta perspectiva, es necesario trasladar los elementos básicos del proceso de comunicación al ámbito educativo, en el cual destacan:

- Emisor, persona, cadena de televisión, un medio impreso, etcétera.

- Receptor, quienes reciben el mensaje.

- Mensaje, es decir, las formas expresivas verbales o no verbales, que poseen el contenido de lo que se desea transmitir. 
- Un medio o canal, ya sea oral, escrito o audiovisual.

- Retroalimentación, la cual permite que el emisor se convierta en un receptor y éste, a su vez, en emisor.

En la educación, estos elementos serian sustituidos por: un educador o instructor, el contenido curricular de la asignatura, el recurso didáctico y las técnicas por las cuales llega el mensaje, los participantes o educandos y finalmente las preguntas, exámenes y comentarios (véase Figura 1).

El elemento adicional que aparece en la figura 1 es el ruido, mismo que en algunos casos no se incluye dentro del proceso comunicativo, pues se considera como un elemento externo, aunque es trascendente en la efectividad de la comunicación de manera similar a lo que Prieto (1999) llama entropía comunicacional en la educación, entendido como la pérdida de sentido.

Un elemento significativo más que incide en el proceso es la sintonía que puede llegar a existir entre el comunicador y el receptor, misma que se determina por el campo de la experiencia que posean; así, conforme éste sea más amplio se facilitará el desarrollo del proceso comunicativo (véase figura 1).

Rodríguez Diéguez (1977: 15-16, citado por Cabero, 2001: 226) esp̃ecifica esta relación en los siguientes términos: "Todo proceso que suponga un transporte de información y cuyo destinatario sea, en último término, el ser humano, lo entenderemos genéricamente como comunicación. Y aquellos procesos de transmisión de información que impliquen el acercamiento entre la configuración actual de un sujeto y la prevista como futura, que logre la modificación de ese sujeto y la prevista como futura, tal que la distancia entre su modo de actuar en situación previa al hecho de recibir el estímulo que determina tal situación, y su modo de operar
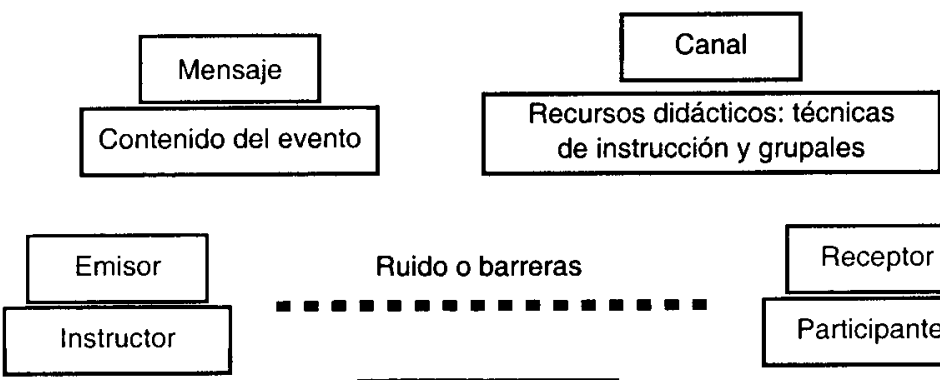

Ruido o barreras
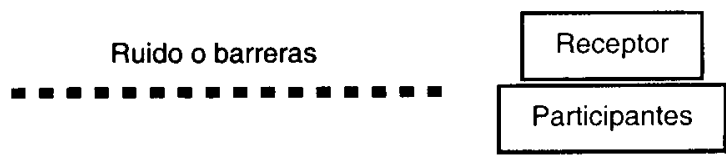

Retroalimentación

Preguntas, comentarios

FIGURA 1. Proceso de comunicación en la enseñanza-aprendizaje 
después de recibir el estímulo -estímulo que supone comunicación- se vea reducida, será comunicación educativa o simplemente comunicación".

Tomando en cuenta lo señalado anteriormente, la Comunicación Educativa (CE) forma parte de la TE, y se puede aseverar que es su base debido a que conlleva un cúmulo de significaciones que afectan el proceso de enseñanza-aprendizaje. Como se puede observar a lo largo de este artículo, el enfoque que se presenta trata de alejarse de la concepción tradicional de la comunicación o modelo informativo en el que no se genera la retroalimentación, para dar paso a una comunicación alternativa que se caracteriza por ser bidireccional, horizontal, y cabe la posibilidad de, que los receptores se conviertan en emisores, diseñadores y creadores de mensajes (Cabero, 2001).

"Para finalizar, no hay que perder de vista que la comunicación educativa no sólo es un proceso de información de mensajes didácticos, sino que al mismo tiempo es un proceso ideológico y de lucha de poderes donde el papel que ocuparán los participantes en el mismo grado de libertad para desenvolverse en él, fuera de los dominios técnicos algunas veces requeridos, dependerá del contexto en el cual se desarrolle" (Cabero, 2001: 230).

\section{Las herramientas tecnológicas en la educación}

Si como se observó los modelos y aspectos teóricos de la comunicación ayudan en la tarea de análisis de los diferentes procesos de enseñanzaaprendizaje, en la actualidad perder el vínculo entre ambos (comunicación y educación) sería equivocado, sobre todo porque la presencia de nuevas herramientas tecnológicas han contribuido a que el ser humano trascienda en el espacio y a que se modifique el proceso de mediación, así como la forma de interacción social y la manera en la que se accede al conocimiento, pues se crea un entorno cultural y educativo capaz de diversificar las fuentes de éste (Delors, 1997).

Históricamente, el inicio del uso sistemático de algún medio de comunicación (además del libro) puede ubicarse en Alemania en el siglo XviII cuando algunos profesores utilizaban periódicos en sus clases y discutían las noticias con sus alumnos. En México, empieza a desarrollarse con la Asociación Prensa en la Escuela, que buscaba diseñar estrategias y técnicas para incorporar el periódico como fuente de información y recurso didáctico en el aula (Orozco, 1997).

El uso pedagógico de las tecnologías de la información y de la comunicación no constituye una novedad, como bien se puede apreciar, pues, por ejemplo, la radio educativa hizo su aparición antes de la Primera Guerra Mundial. Sin embargo, desde la perspectiva de Delors (1997: 194), "no es la gama de las tecnologías empleadas y su grado de complejidad 
lo que ha cambiado con el tiempo sino también la voluntad de dirigirse, más allá del sistema escolar formal, a una variedad de públicos cada vez más amplia y de todas las edades".

Hablar de los medios y la educación significa abordar un campo que incluye no pocos aspectos, ya que son en principio agentes de formación y socialización que ocupan un lugar central en la vida de las personas (Morduchowicz, 2001). Tradicionalmente, los medios de comunicación -incluyendo el cine-, fueron considerados por los intelectuales como influencias negativas que amenazaban la cultura, pero después, el marco socioeducativo fue evolucionando para aceptar, aunque no del todo, que "la escuela debería estar capacitada para enfrentarse a los medios, ilustrando sus contenidos e interpretando sus formas, transformándolos en un conjunto coherente" (Pérez, 2000: 181).

No se puede negar el poder de convocatoria que tienen los medios, y tampoco puede olvidarse el efecto educativo, tanto cuando es intencional como cuando es involuntario: son educadores, para bien o para mal. Educar, en el sentido etimológico del término: e-ducere, es externar de dentro hacia fuera, obtener a alguien de sí mismo, ayudarle para que se mueva, impulsarle a ir más allá cada vez, apoyarle en el desarrollo de lo que ya está en él de manera embrionaria, hacer surgir lo que está de manera latente, como en el revelado de las fotografías, para continuar con la tarea del aprendizaje durante toda la vida.

"De acuerdo con la tendencia educativa problematizadora y el esquema de comunicación alternativo, la incorporación de los medios a la escuela es una forma de generar procesos cualitativos de aprendizaje y una formación integral en la medida en la que recuperemos todos los conocimientos que se adquieren por todos los medios" (Luviano y Alonso, 1997: 32).

Las diferentes formas, aunque complementarias, de vincular los medios a la educación son tres (Orozco, 1997: 17):

- Como instrumentos didácticos. Cumplen con la función de diversificar la presentación de la información, hacer más eficiente y eficaz el proceso de enseñanza-aprendizaje, integrar distintas "aristas" de los objetos del conocimiento, y emplear diversos recursos, lenguajes y códigos para buscar un aprendizaje más integral.

- Como medios de expresión. Cada medio tiene su lenguaje específico y su forma particular de orquestar los contenidos a partir de sus características específicas.

- Como fuente de contenidos. Complemento de la información escolar, cuyo objetivo es aprovechar la información que los medios codifican y transmiten a su público. 
La TE interesada en los puntos anteriores, trata de vincularse con los tres incisos, aunque prevalece una marcada tendencia a relacionarla con el primero -instrumentos didácticos- Desde este punto de vista aprender con medios es, fundamentalmente una actividad individual que se produce en un contexto determinado en el que intervienen múltiples factores de diversa naturaleza (cognitivos, actitudinales, organizacionales, etcétera) que deben ser considerados en un proceso educativo formal al incorporar la tecnología en el aprendizaje.

Desde la perspectiva de Salomón (1979, citado por Área, 2002), uno de los autores representativos y más destacados en el campo de los medios, los atributos específicos de todo medio son:

a) Los tecnológicos, que afectan la difusión de la información. Se ha demostrado que, cuando lo único que cambia en una situación de aprendizaje es sólo la tecnología, sus efectos en el aprendizaje no son eficaces.

b) Los contenidos, son el propósito primario y de mayor interés para un número considerable de pedagogos. Sin embargo, no se ha encontrado una relación clara y precisa entre los distintos medios y la vinculación con determinados contenidos.

c) Marcos y situaciones sociales, asociados al uso que se realice de los medios. En determinados contextos y condiciones de uso, el efecto de los medios en el aprendizaje varía significativamente.

d) Los sistemas de símbolos, definidos como un conjunto de elementos que representan campos de referencia que se asocian con ciertas reglas o convenciones.

Por tanto, "un sistema de símbolos comunica mejor que otro no a causa de un parecido entre el símbolo representado y su referente, sino porque un sistema de símbolos, en comparación con otros, puede presentar la información en mejor correspondencia al $\longrightarrow$ en congruencia con el- modelo de representación que un individuo, con una determinada estructura cognitiva y una tarea dada, puede utilizar mejor" (Área, 2002: 11). Cuando una persona interactúa con un medio, el conocimiento es codificado de manera diferente a la tradicional (libro), desarrolla diferentes habilidades, la actividad mental requerida depende de las características de los sujetos y el mismo recurso tecnológico, etcétera.

Como se observa en la figura 2 , los efectos de los medios de enseñanza dependerán en gran medida de la interacción entre variables.

Aún considerando lo explicado en renglones anteriores, independientemente de que las nuevas tecnologías posean características tales como: inmaterialidad, interactividad, instantaneidad, innovación, calidad de imagen, sonido, digitalización, automatización, interconectividad y otras más (Cabero, 2002), hay atributos que las diferencian entre sí, lo cual acentúa su funcionalidad para determinados contenidos y objetivos temáticos particulares. 


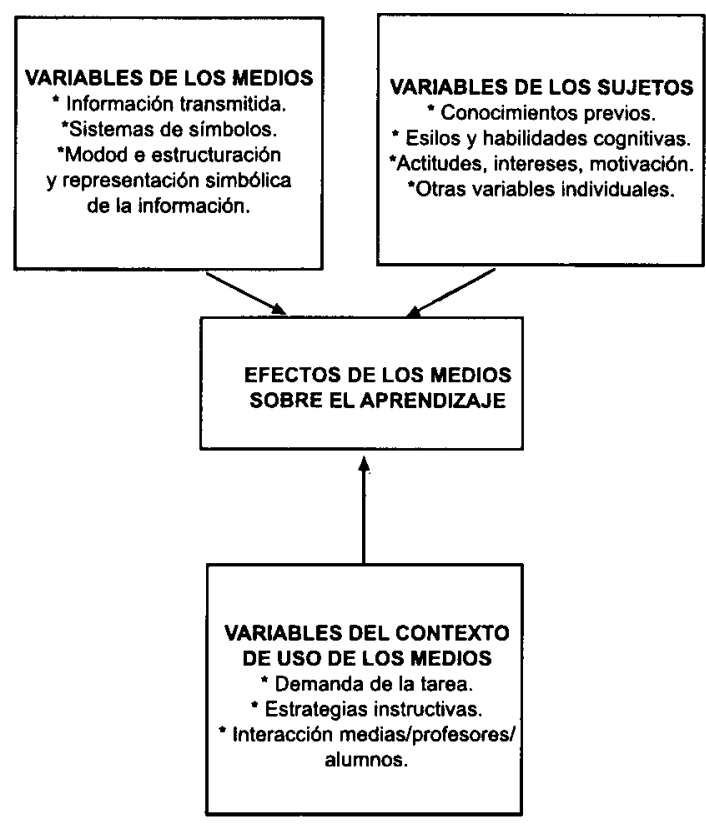

\section{FIGURA 2. Efectos de los medios de aprendizaje}

Así, en el proceso de comunicación, el medio es el intermediario que transporta los mensajes a través del espacio y el tiempo. Es una "organización de recursos que media la expresión de acción entre maestro y alumno" (Castañeda, 1979: 103).

\section{Las herramientas tecnológicas y su uso didáctico}

En tanto que las nuevas generaciones sobrellevan la influencia de la comunicación social en sus vidas, la educación no puede permanecer al margen de esta realidad. El contexto requiere de estrategias educativas innovadoras que sean capaces de integrar los nuevos medios didácticos y tecnologías informativas en las aulas con la finalidad de ofrecer a los educandos los conocimientos necesarios para entender los nuevos lenguajes audiovisuales, aprender a través de ellos y emplearlos como nuevos códigos de expresión e interpretación del mundo (Aguaded y Cabero, 1995).

Ha llegado el tiempo de incorporar al tradicional libro de texto y al pizarrón recursos pedagógicos que van desde los visuales como el retroproyector y el proyector de diapositivas, a los audiovisuales como el video, sin olvidar el medio informático —n sus inicios básicamente se utilizaba en los centros para el tratamiento cuantitativo de datos, el proce- 
samiento y manipulación de textos y el aprendizaje de determinados lenguajes de programación en la búsqueda de una ampliación cognitivaque ha visto ampliadas sus posibilidades con la creación de entornos simulados, hipertexto y multimedia.

El sistema escolar debe prepararse para recibir estas herramientas tecnológicas, no puede permanecer al margen; en definitiva, su papel no sólo se centra en tener los recursos tecnológicos, sino también los recursos humanos (en este caso los docentes) capacitados y habilitados para usar didácticamente al video, el proyector de acetatos, de diapositivas, la computadora o cualquier otro medio que resulte útil en el proceso de enseñanza-aprendizaje. La responsabilidad trasciende a los directivos y a todos los involucrados en actividades docentes.

Aunque cada medio posee características particulares y su forma de uso depende de ello, existen estrategias que pueden ser utilizadas $\sin$ importar el tipo de recurso del que se trate. Por ejemplo, en el caso del video, éste puede (Educación Secundaria, 1996):

- Suscitar el interés sobre un tema. Provoca una respuesta activa, problematiza un hecho, estimula la participación o promueve actitudes de investigación. El video atrae la atención sobre un tema sin desarrollar necesariamente el contenido. Los programas utilizados con este fin deben ser muy breves, con un mensaje muy claro y llamativo que capture la atención y el interés.

- Introducir un tema. Utilizado como introducción, proporciona una visión general del tema, a partir de la cual el maestro puede destacar los conceptos básicos que se analizarán, aclarar la importancia de abordar el estudio de tal situación, hecho o problema, y proponer las actividades que se desarrollarán. A partir de su presentación, se propondrá la realización de otras actividades de estudio.

- Desarrollar un tema. En este caso, el video apoya las explicaciones del profesor de manera semejante a como se utiliza un rotafolio, una serie de acetatos, el proyector de cuerpos opacos o un libro durante la clase.

- Confrontar o contrastar ideas o enfoques. Existen programas en los que se presenta la opinión de expertos, científicos o representantes de grupos de opinión. Su uso en clase permitirá a los alumnos establecer comparaciones y contrastar diferentes puntos de vista, lo que aportará un elemento más al conocimiento que posean acerca del tema. Se apela a la capacidad de análisis y a la deducción.

- Recapitulación o cierre de un tema. Utilización de ciertas imágenes o segmentos de un video para constatar el aprendizaje de los alumnos como resultado de las actividades realizadas en torno de un tema o problema. Esta modalidad también permite el uso del video después de una mesa redonda, discusión en grupo o debate para aclarar la información, ampliar y profundizar o concluir un tema. 
Dichos usos no sólo aplican al video, pese a estar enfocados en él, las estrategias pueden ser incorporadas en la utilización didáctica de otros recursos como el proyector de acetatos e incluso la computadora a través de las diapositivas de power point que requieren de un aparato adicional como el cañón para su proyección. Sin embargo, no debe perderse de vista que dependiendo de las características técnicas y discursivas del medio algunos presentan particularidades.

El proyector de acetatos es un caso en el que adicionalmente a los usos del video (que como ya se mencionó pueden aplicar a otro medio), posee tres estrategias diferentes desde la perspectiva de Cebrián (2000):

- La parcelación. Consiste en tapar temporalmente una parte de la transparencia con un cuerpo opaco - una hoja, formas intencionadas, etcétera- y dejar al descubierto aquellas partes que están siendo de utilidad para el momento de la conferencia o clase.

- La semipreparación. La transparencia no contiene la totalidad de lo que debemos exponer por diferentes motivos; se trata de una transparencia incompleta, que incluye el esquema de un desarrollo, datos numéricos, etcétera y el resto debe incorporarse a mediada que ąvanza el discurso (transparencia base).

- La superposición. Se trata de colocar transparencias sobre transparencias hasta que su visibilidad nos lo permita. En cada transparencia pondremos partes sumatorias del total de la composición que queremos ofrecer. Supone la elaboración de una serie que forma un conjunto a mostrar en etapas (transparencias matriz y de ejercicio).

Con la panorámica sobre el uso didáctico del equipo técnico con el que podrian contar las diversas instituciones educativas, es importante ahora aterrizar estas nociones en la realidad. Dada la complejidad institucional y variedad sociocultural de las diversas escuelas de comunicación en el país, enseguida se realiza una reflexión entorno a lo que sucede en la Universidad Latina de América en relación al uso didáctico que los docentes dan a las diferentes herramientas tecnológicas con que cuenta esta institución.

\section{La Licenciatura de Ciencias de la Comunicación de la UNLA}

La Licenciatura de Ciencias de la Comunicación (ICC) de la UNLA fue creada hace 11 años con el objetivo de formar profesionistas teórica, técnica y humanísticamente integrados, capaces de manejar las distintas disciplinas que comprende la comunicación y los diversos lenguajes, para la producción de mensajes con un alto compromiso para con su entorno y realidad social. 
En la actualidad con un promedio de 250 alumnos, esa licenciatura es la que cuenta con la matrícula más grande de la UNLA. Además de contar con una planta docente de cátedra que semestre con semestre oscila entre los 30 y 35 profesores, cuenta con su laboratorio de radio, televisión y fotografia. Sin embargo, en lo que respecta al equipo tecnológico como televisiones, videos, proyectores, cañones y computadoras, la LCC lo comparte con el resto de los programas académicos de la universidad.

La distribución del equipo en los dos edificios que tiene la institución es de la siguiente manera:

En el edificio " $A$ " (dos pisos con 10 salones en total) se cuenta con 8 televisiones, 8 videograbadoras, 4 DVD, 8 computadoras, 8 cañones, 4 proyectores de acetatos y 2 proyectores de diapositivas.

En el edificio "B" (cuatro pisos con un promedio de 40 salones en total) se tienen 9 televisiones, 8 videograbadoras, $2 \mathrm{DVD}, 15$ proyectores de acetatos, 4 proyectores de diapositivas, 1 computadora, 1 grabadora y ningún cañón.

Cabe señalar que para tener acceso a cualquier apoyo tecnológico se debe hacer una solicitud por escrito, en algunos casos 10 minutos antes de que inicie la clase o bien, si se trata de salones equipados con todo (cañón, computadora, televisión y video), con una o hasta con dos semanas de anticipación.

\section{Metodología general}

Considerando el papel que tiene la CE dentro del proceso de enseñanzaaprendizaje y también como parte de la $\mathrm{TE}$, un primer acercamiento a la realidad para vislumbrar orientaciones acerca del uso didáctico de herramientas tecnológicas en el aula es observar si los profesores de Ciencias de la Comunicación emplean estas tecnologías, cuáles predominan, de qué manera las incorporan al salón, y cómo las eligen, mediante un cuestionario aplicàdo a 31 docentes de los 36 que conformaron el cuerpo académico durante el semestre Primavera 2004 (enero-mayo) de la LCC de la UNLA.

Cabe señalar que los resultados corresponden a un estudio con base en el método descriptivo, de corte no experimental de tipo transversal, apoyado en técnicas cuantitativas (cuestionario conformado por 15 preguntas abiertas y cerradas para los docentes).

\section{Análisis e interpretación de datos}

Los resultados obtenidos a través del cuestionario que se aplicó a los docentes de la LCC de la UNLA, indican que la media de los años de 
¿Utiliza herramientas tecnológicas en el proceso de enseñanzaaprendizaje?
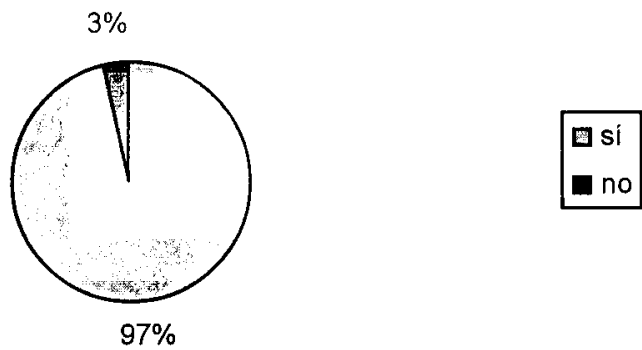

FIGURA 3. Uso de las berramientas tecnológicas

en el proceso de enseñanza-aprendizaje

experiencia que poseen los profesores en la actividad docente se sitúa entre los 3 y 10 años. Situación que, como se observa, no afecta la utilización de recursos tecnológicos en el proceso de enseñanza-aprendizaje, puesto que la mayoría recurre a ésta (véase figura 3). Cabe señalar que en este caso se entiende por recurso tecnológico al video, televisión, proyector de acetatos, proyector de diapositivas, grabadoras, cañón y computadora debido a que son los materiales con los que cuenta la UNLA.

Ahora bien, si se toma en cuenta el motivo por el cual emplean la tecnología en el aula, predominó con $22 \%$ su tarea como facilitadora del proceso de enseñanza-aprendizaje; al respecto, es importante señalar que, dado que la pregunta fue abierta, se agruparon por rangos las respuestas proporcionadas por los docentes, de tal forma que el porcentaje referido anteriormente agrupa sólo a quienes señalaron la facilitación del proceso educativo. El resto de las respuestas hace alusión en su mayoría a los atributos tecnológicos (63\%), ya que el aspecto visual (21\%) y lo atractivo del medio (21\%) así lo connotan.

Es de llamar la atención que, pese a que el tiempo es un factor determinante en las dinámicas de aprendizaje, no fue tomado en cuenta por los profesores a quienes se encuestó, ya que sólo $6 \%$ de ellos piensa utilizar como apoyo herramientas tecnológicas como medida para optimizar la duración de sus clases. En ese sentido se olvida que el recurso temporal refleja una planeación previa del ambiente adecuado para el desempeño de las labores académicas; entonces, ¿los docentes no planean sus clases? o bien, ¿planean sin considerar que el tiempo delimita su actividades?

Por otro lado, y con base en los resultados, se observa congruencia entre por qué los docentes usan más cierto recurso tecnológico en el aula 
( $50 \%$ dice que es adecuado para el contenido) y el criterio a partir del el cual se selecciona y emplea, ya que $51 \%$ de los encuestados señala que el objetivo y contenido es lo primero en lo cual piensan para incorporarlo. No obstante, muchas de las ocasiones la elección del medio se ve supeditada a la disponibilidad del equipo porque, a lo mejor, para una clase se requiere cañón y computadora, pero como no hay suficientes se opta por suplir ese medio con otro, en este caso la televisión o el proyector de acetatos que en ocasiones no va de acuerdo ni con los objetivos de la asignatura, ni con el tema que se verá.

En este sentido es que se puede deducir por qué el proyector de acetatos es el medio más empleado por los docentes con un $32 \%$, ya que la universidad cuenta con mayor número de éstos (un total de 19) entre los edificios "A" y "B". Le sigue el video (27\%), puesto que hay 17 televisiones y 16 videograbadoras en la institución. Finalmente, la computadora ocupa el tercer lugar (25\%) debido a que el equipo con el que se cuenta es insuficiente (figura 4). Se deduce que la utilización de un recurso se define por la disponibilidad del equipo y por la infraestructura de la institución, lo cual puede generar la habituación a un medio debido a que es lo único con que se cuenta.

El recurso tecnológico que se usa menos con $14 \%$, es el proyector de diapositivas, ello quizá debido a que no hay cortinas en todos los salones como para oscurecer el espacio y a que el número de proyectores es insuficiente ( 6 en toda la universidad).

En cuanto a las funciones didácticas de los recursos tecnológicos en el aula, cabe señalar que las respuestas fueron de opción múltiple, lo cual pudo condicionar, en un momento dado, la respuesta al proporcionar indicios al docente sobre su empleo, incluso sin saber con precisión de la temática. $34 \%$ ejemplifica a través de los medios y $31 \%$ desarrolla los

¿Cuál es el recurso tecnológico que más emplea en el aula?

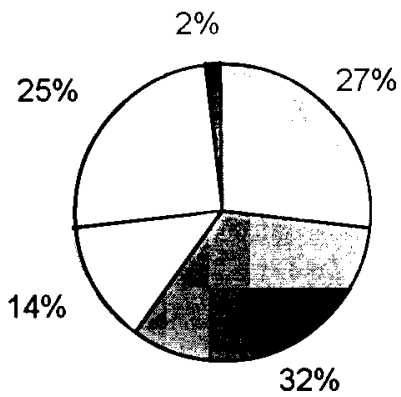

$\square$ video
$\square$ proyector de acetatos
$\square$ proyector de diapositivas
$\square$ computadora
$\square$ otros

FIGURA 4. Recurso tecnológico más empleado 
temas (véase figura 5); pese a que no había otras opciones adicionales en este sentido, nadie, con excepción de una persona, mencionaron la introducción al tema, el cierre de la clase, establecimiento de puntos de vista distintos, contrastación o, como lo señaló el $1 \%$, en la opción otros: estudios de caso y resolución de problemas. Esto revela el perfil de empleo dentro del espacio de enseñanza-aprendizaje y la necesidad de que los profesores se involucren más con la incorporación didáctica de las herramientas tecnológicas en el aula.

Los resultados dejan entrever que, pese a que los docentes conocen un poco acerca de algunas estrategias, falta profundizar específicamente sobre los usos particulares de cada medio, ello en función de las características, ventajas y desventajas que presentan. Asimismo, se debe apuntar que, aunque algunos de los encuestados tienen conocimiento de usos diferentes a los propuestos, 'es posible que no se hayan acordado en el momento del nombre de la función o que, incluso, lo empleen sin saber que aquello es una estrategia.

Los problemas recurrentes que se desprenden del uso de los medios en el aula se orientan en un $44 \%$ a la disponibilidad del equipo, y es que, en ocasiones, en la UNLA el proceso de solicitud de equipo a través de personal de seguridad es tardado, no hay suficientes aparatos o se descomponen con frecuencia (23\%). $27 \%$ indicó que no tenía problemas al momento de utilizar los medios en el aula. A partir de esto se puede inferir la necesidad de una mayor disponibilidad de equipo en la UNLA.

La actitud de los alumnos cuando se usa tecnología en el salón varía, ya que $87 \%$ manifestó que se mostraba activo e interesado (véase figura 6 ), mientras que sin esos recursos adicionales $57 \%$ indicó que permanecía pasivo (véase figura 7).

¿Para qué utiliza los recursos tecnológicos en el aula?

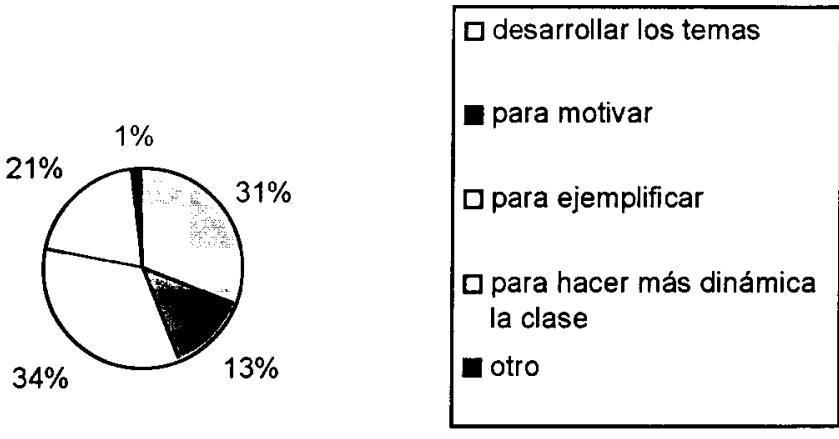

FIGURA 5. Uso de la tecnología en el aula (funciones) 
Cuando utiliza recursos tecnológicos en el aula, el alumno se muestra

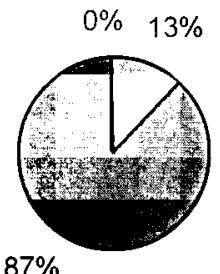

$\square$ pasivo

activo e interesado

$\square$ desinteresado

$87 \%$

FIGURA 6. Actitud del alumno frente al uso de la tecnología en clase

Conforme a la situación, cabría preguntar cómo es que los docentes dan por hecho si el alumno se encuentra en un estado pasivo o no, cuáles son esas variables, ya que un $39 \%$ comentó que la actitud del alumno sin tecnología sigue siendo de actividad e interés (véase figura 8 ). No se debe ignorar que la mera tecnología no soluciona los problemas educativos que se presentan en el proceso de enseñanza-aprendizaje, el punto es su forma de incorporación de la que dependerán las dinámicas y estrategias de la clase, de ahí la pertinencia de recordar a la TE en los términos de García-Valcárcel (2003), como un espacio que se ocupa no

\section{Cuando no emplea recursos tecnológicos en el aula, el alumno se muestra...}

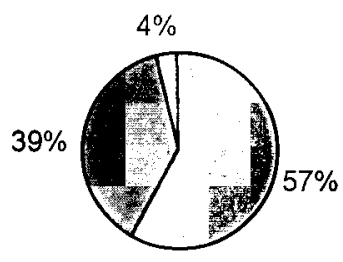

\begin{tabular}{|l}
\hline pasivo \\
activo e interesado \\
$\square$ desinteresado
\end{tabular}

FIGURA 7. Actitud del alumno en clase sin el uso de la tecnología 
sólo de aspectos aplicados (diseño de medios y materiales, diseño curricular, propuestas para resolver problemáticas a las que se enfrentan los docentes en la práxis educativa, etcétera), sino también de reflexiones y teorías sobre lo que representan para la enseñanza los medios desde el punto de vista didáctico, comunicativo y social.

Los resultados a las dos interrogantes anteriores posibilitan preguntar a qué se debe la actitud pasiva del alumno y cuál es una actitud pasiva, ya que el medio por sí mismo no genera actividad o pasividad, es el docente, con sus estrategias quien lo logra; por otro lado, la conceptualización de la pasividad requiere especial atención, puesto que no implica que todo alumno que esté callado y sin participar en clase haciendo preguntas sea pasivo.

Entonces, al hablar de la existencia de posibles cambios en el proceso de enseñanza-aprendizaje tras la incorporación de tecnología, la respuesta de los docentes encuestados es positiva en $80 \%$, pues señalan que hay un mayor interés, participación y motivación en los alumnos, así como una mejor comprensión de los temas (véase figura 8). Sin embargo, estas respuestas orillan al investigador a preguntarse acerca del modo en el que los profesores corroboran que esto es así; quizá sea la evaluación sistemática y la constante reflexión, encaminada al mejoramiento de la práxis educativa, la que pueda contribuir a desarrollar un uso racional de la tecnología en la educación basada en objetivos específicos que involucren el "todo", desde los contenidos - como lo señalaban los encuestados en sus respuestas - hasta el contexto, la institución escolar e inclinaciones personales del profesor.

\section{¿Cuáles son los cambios que observa?}

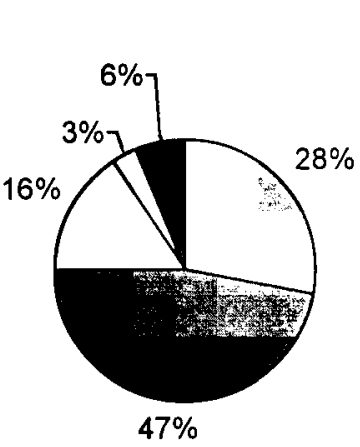

\begin{tabular}{l}
\hline mayor comprensión de \\
los temas \\
mayor interés, \\
participación y \\
motivación \\
propicia las discusiones \\
y reflexiones \\
se genera mayor \\
interacción \\
el aprendizaje mediante \\
la tecnología se vuelve \\
cotidiano
\end{tabular}

FIGURA 8. Cambios observados en el proceso de enseñanza-aprendizaje con el uso de la tecnología 
El conocimiento que posee acerca del uso de las herramientas tecnológicas en el aula lo tiene gracias a:

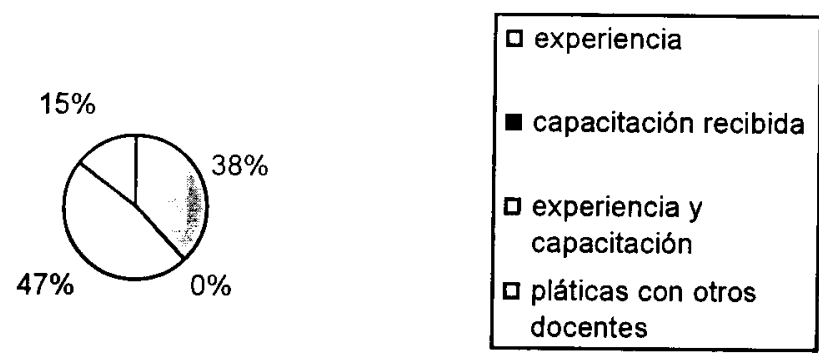

FIGURA 9. Fuente del conocimiento sobre el uso de la tecnología en el aula

Como se observa en la figura 9, aunque los docentes dicen emplear la tecnología con base en la capacitación recibida y experiencia, ello requeriría verificación mediante un trabajo experimental (observación de clases) a través del cual se constate que efectivamente tienen el conocimiento del uso didáctico de las herramientas tecnológicas. Este proceso contribuiria, además, a clarificar si es necesaria o no la capacitación para los profesores en el área del manejo técnico, utilización pedagógica o la lectura crítica (véase figura 10).

Si recibió capacitación sobre el empleo de las tecnologías

en el salón de clase, ¿cuál fue su orientación?

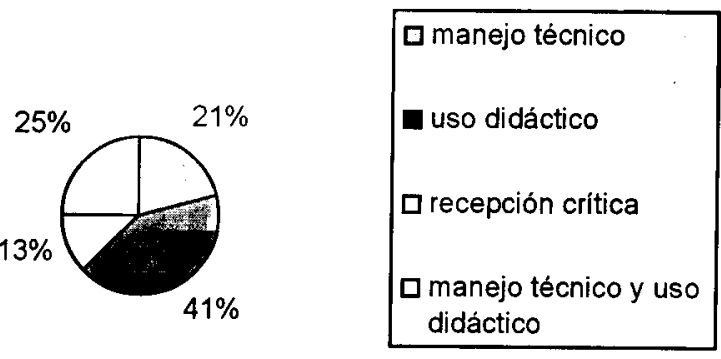

FIGURA 10. Orientación de la capacitación recibida por los docentes sobre el uso de la tecnología en el aula 
Finalmente, la opinión de los docentes en cuanto al uso de la tecnología se coloca en una perspectiva positiva, pues sólo $2 \%$ indicó que fomenta la pasividad o que son poco funcionales en nuestro contexto. $49 \%$ señaló que fomenta habilidades y destrezas diferentes a las habituales y que además resulta una herramienta eficaz para motivar, según $27 \%$. No obstante, no se especifican los tipos de habilidades o destrezas que se desarrollan y aquí se tendría que hacer un paréntesis, pues éstas dependerán de la herramienta tecnológica en particular de la que se trate y del diseño que el profesor haga para su incorporación dentro del salón de clases.

\section{Conclusiones}

Con base en los resultados obtenidos, queda evidenciado que la educación en la actualidad es afectada por múltiples factores, como el desarrollo tecnológico, que repercuten en la forma en la que se venía concibiendo el saber, la manera de acceder a él y los papeles que desempeñaban tanto el docente como el alumno en esta dinámica. La escuela, ante tal situación, no puede menos que repensar la orientación de sus prácticas, ya que los sujetos que aprenden son receptáculos de los aprendizajes a partir de sus experiencias de vida, en las que, desde luego, están los medios de comunicación masiva y las nuevas tecnologías de información como la computadora e internet. El aislamiento ya no es la solución, la negación de lo que permanece latente no es tampoco el camino; de lo que se trata es de incorporar estos nuevos lenguajes al aula con una finalidad diferente a la del uso comercial, es decir, recurrir y explorar sus potencialidades para enseñar y educar.

No basta solamente con emplear como recursos didácticos las nuevas tecnologías de información, se requiere contar con la habilidad y capacidad suficientes para que su funcionamiento e incorporación sean óptimos, cuestión que se logra a través no sólo de la experiencia, sino además de la capacitación especializada que tengan acerca de éstos quienes los utilizan: prioritariamente los docentes. En tanto que la educación no puede desarrollarse a espaldas de las innovaciones, queda entonces la posibilidad de integrar los recursos tecnológicos como apoyos didácticos de manera cotidiana para la formación del educando, en donde se busque contribuir al enriquecimiento de la inteligencia humana y social. Desde esta perspectiva, la educación no es más una reserva académica, es vista como una tarea global que contribuye al enfrentamiento con el mundo, además de ser un recurso que conjunta hábitos perceptivos y procesos mentales distintos a los de la lectura habitual.

Dadas las características de nuestro entorno global, se hace necesario cada vez más que en las escuelas, los docentes sean los primeros en saber incorporar las herramientas tecnológicas adecuadamente a sus cla- 
ses, pues de esta forma se podrá enriquecer la explicación, y el grado de vulnerabilidad frente a los alumnos en el empleo de las tecnologías comenzará a revertirse. Frente a la cultura mediática en la que están inmersos los jóvenes, la labor del profesor es llevar a su entorno de trabajo aquellos mecanismos o herramientas que permitan un desarrollo óptimo del proceso de aprendizaje.

La implementación de recursos como el proyector de acetatos o diapositivas, el video e incluso la computadora en el aula constituye una estrategia favorable en la educación formal, pues debido a sus características técnicas es posible la reproducción de imágenes fijas o en movimiento, sonido, colores y formas cuyo resultado en el alumno es la mejor visualización de algunos conocimientos, así como la simulación de procesos que de otra forma serían más complicados de entender. El uso de estas alternativas permite, además, una mayor observación, esa que a veces pierden los jóvenes en clase cuando ya no saben disimular los bostezos.

Aprender a hacer un adecuado uso de las tecnologías es tarea que interesa a quienes desempeñan funciones académicas en alguna institución, de ahí la importancia de este trabajo, puesto que va más allá de identificar las formas más usuales de empleo de las tecnologías en la Licenciatura de Ciencias de la Comunicación: se pretende que a partir de los resultados se genere una propuesta de aplicación de la TE, iniciando con uno de los participantes centrales del proceso de enseñanza-aprendizaje: el docente.

Con respecto a la pregunta de investigación realizada "¿Cómo están utilizando la TE los profesores de Ciencias de la Comunicación y de qué manera se puede eficientar el desarrollo del proceso de enseñanza-aprendizaje?" La respuesta es que su uso responde en parte a la capacitación con que cuente la persona que educa, pero también depende de los recursos con que cuenta la institución y la disponibilidad que ésta tiene para formar a su personal en las áreas de su interés.

Asimismo, y en función de las preguntas secundarias de investigación, se llegó a la conclusión de que en la LCC recurrir al uso de la tecnología es frecuente, ello debido quizá a que la misma línea de la carrera y el objetivo de la misma requiere preparar jóvenes teórica, técnica y humanísticamente integrados, capaces de manejar las distintas disciplinas que comprende la comunicación y sus diversos lenguajes. No obstante, si se desea formar a un profesional con determinadas características, quienes lo enseñan (los docentes) deben estar preparados para hacerlo, de ahí que sea importante considerar el perfil de éste al momento de su contratación.

Ahora bien, el motivo por el cual la tecnología se emplea es porque resulta motivante para los alumnos, ya que los contenidos se presentan 
en forma atractiva gracias a su dinamismo, y colores; incluso, simplemente por el hecho de presentar imágenes aun sin movimiento las clases se parecen más a aquello con lo que acostumbran estar en contacto (televisión, radio, video juegos, etcétera). Cabe señalar que las herramientas más utilizadas fueron el proyector de acetatos y el video, ya que piensan que son adecuados para los contenidos, pero al contrastarlo con el resto de la información y otras preguntas del cuestionario se llegó a la conclusión de que se debía en todo caso a su disponibilidad.

Resumiendo lo aseverado en líneas anteriores se puede concluir de la siguiente manera:

- La experiencia docente no tiene relación con la incorporación de la tecnología en el aula.

- Los docentes reconocen la utilidad del empleo de la tecnología en el salón de clase, sobre todo en lo que respecta a la facilitación del proceso de enseñanza-aprendizaje y al soporte visual que hacen más atractivos los contenidos. Aunque ciertamente esto no es lo único que hace más o menos atractiva una clase.

- El recurso que más se emplea es el proyector de acetatos, ello pese a que contestaron que por el contenido, después se constató qué se debía a la disponibilidad. No se usa la computadora porque no hay muchos aparatos y porque los cañones son insuficientes.

- La estrategia de uso de medios, no es aún muy clara para los docentes, ya que a pesar de que manifiestan conocer algunos usos, ni son todas las estrategias, ni mucho menos existe conciencia de las funciones de acuerdo a las particularidades del medio.

- Los cambios que se observan en los alumnos al emplear tecnología en el aula no son contundentes, pues incluso cuando no se emplea se puede llegar a generar participación. Es prudente aseverar que, en todo caso, el cambio en el comportamiento o actitud del alumno depende de las estrategias que pone en práctica el profesor; el medio es sólo eso.

- Es necesaria la incorporación de la TE en la propuesta educativa de la LCC, puesto que a partir de ello, los egresados podrán responder a las nuevas competencias que exige la sociedad de la información tanto en el aspecto cognitivo, como en el metacognitivo y el social. La idea surge de ver que en la TE se convierte al proceso de aprendizaje en un proceso comunicativo que busca comprender totalmente el quehacer didáctico, sus debilidades y sus fortalezas.

- La respuesta a varias preguntas que se desprenden de esta investigación deben ser encontradas mediante un análisis experimental del uso didáctico de las herramientas tecnológicas en el aula, ya que las encuestas sólo proporcionaron información desde la perspectiva de los maestros y no de los alumnos, ni de la práxis educativa. Resulta 
pertinente continuar con los trabajos sobre la TE en las Ciencias de la Comunicación mediante la triangulación de datos que permita obtener mayor detalle y desde variadas perspectivas, una construcción global. La dinámica inmediata sería la observación de clases y el seguimiento de las mismas a través de una bitácora.

- Por último, es importante llegar a descubrir si existe relación directa entre los contenidos de las asignaturas y los medios, ya que podría hacerse un inventario con estrategias de acuerdo a las materias del programa de Ciencias de la Comunicación y las características de cada herramienta tecnológica.

\section{Referencias}

Aguaded, J. y J. Cabero, (1995), "Educación y medios de comunicación en el contexto latinoamericano", en Encuentros Iberoamericanos 1, Universidad Internacional de Andalucía, España.

Área, M. (2002), "Los medios y materiales de enseñanza. Fundamentos conceptuales", en Web docente de tecnología educativa, Universidad de la Laguna.

Cabero, J. (2001), Tecnología educativa. Diseño y utilización de medios en la enseñanza, Paidós, Barcelona.

-, "Nuevas tecnologías, comunicación y educación", Comunicar, 3, pp. 14-25.

Castañeda, M. (1979), Los medios de la comunicación y la tecnología educativa, Trillas, México.

Cebrián, M. (2000), El retroproyector. Recuperado el 05 de mayo de 2004, de http://wwww.ieev.uma.es/biblos/material/mater/031.htm.

Delors, J. (1997), La educación encierra un tesoro, UNESCO, México.

Educación secundaria (1996), El video en el aula. Acervo y usos didácticos de la videoteca escolar, SEP, México.

Escamilla, J. G. (1998), Selección y uso de tecnologia educativa, Trillas, ILCE/UV/ ITESM, México.

Fainhole, B. (2001), La tecnologia educativa apropiada: una revisita a su campo a comienzos de siglo. Recuperado el 07 de marzo de 2004, del Web de la Universidad Autónoma de Barcelona: http://dewey.uab.es/pmarques/EVTE/ fainholc4.doc

Ferrer, E. (1997), Información y comunicación, FCE, México.

García-Varcárcel, A. (2003), Educación y tecnología. Recuperado el 07 de marzo de 2004, de la Web de la Universidad de Salamanca: http://web.usal.es/ ranagv/artil.htm

Luviano, Guadalupe y Aurora Alonso (1997), Comunicación y educación: SEP/ ILCE/UPN, México.

Maldonado, H. (1998), Manual de comunicación oral, Pearson, México .

Marqués, P. (1999), El desarrollo de la tecnologia educativa, recuperado el 07 de marzo de 2004, de la Web de la Universidad Autónoma de Barcelona: http:// dewey.uab.es/pmarques/tec.htm 
Morduchowicz, R. (2001), "Los medios de comunicación y la educación: un binomio posible", en Revista Iberoamericana de Educación, 26. Recuperado el 03 de marzo de 2004, de http://campus-oei.org/revista/rie26a05.htm

Orozco, G. (1997), Año 2000: Odisea de los medios de comunicación, SEP/ILCE/ UPN, México.

Pérez, J. M. (2000), Comunicación y educación en la sociedad de la información. Nuevos lenguajes y conciencia crítica, Paidós, Barcelona .

Prieto, D. (1999), La comunicación en la educación, ciccus/La Crujía, Argentina. 